\title{
Family Resilience: A Framework for Clinical Practice
}

Froma Walsh, Ph.D.

This article presents an overview of a family resilience framework developed for clinical practice, and describes its advantages. Drawing together findings from studies of individual resilience and research on effective family functioning. key processes in family resilience are outlined in three domains: family belief systems, organizational palterns, and communication/problem-solving. Clinical practice applications are described briefly to suggest the broad utility of this conceplual frameuork for intervention and prevention efforts to strengthen families facing senious life challenges.

Fòm Proc 42:1-18, 2003

\section{A FAMILY RESILIENCE FRAMEWORK}

7 the concept of family resilience extends 1 our understanding of healthy family functioning to situations of adversity. Although some families are shattered by crisis or chronic stresses, what is

Froma Walsh, School of Social Service Administration and Department of Psychiatry. and Center for Family.Health. University of Chicago.

Correspondance concerning this article should be addressed to Froma Walsh. Ph.D., 969 E 60th Street, Chicago, 11linois 60637. E-mail: fwalsh@uchicago.edu remarkable is that many-others emerge strengthened and more resourceful.

Resilience-the ability to withstand and rebound from disruptive: life challengeshas become arimportant concept in mental health theory and research over the past two decades. It involves dynamic processes fostering positive adaptation within the context of significant adversity (Luthar, Cicchetti, \& Becker, 2000). These strengths and resources enable individuals and families to respond successfully to crises and persistent challenges and to recoyer and grow from those experiences (Cowan, Cowan, \& Schultz, 1996). Some who have suffered trauma become blocked from growth or trapped in a victim position. In contrast, resilience involves key processes over time that foster the ability to "struggle well," surmount obstacles, and go on to live and love fully.

\section{The Relational Context of Individual Resilience}

Most research to date has focused on individual resilience. In the 1980 s, increasing evidence was found that the same adversity may result in different outcomes, which challenged the prevailing deterministic assumption that traumatic experiences, especially in childhood, are inevitably damaging. In surveying these findings, Rutter (1987) noted that no combination of risk factiors, regardless of severity, gave rise to disorder in more 
than half the children exposed. Although many lives were shattered, others overcame similar high-risk-conditions and were able to lead loving and productive lives and to raise their children well. Studies found, for instance, that most abused children did not become abusive parents (Kaufman \& Ziegler, 1987).

To account for these differences, early studies focused on personal traits for resilience, or hardiness, reflecting the dominant cultural ethos of the "rugged individual" (Luthar \& Ziegler, 1991; Walsh, 1996). Initially, resilience was viewed as innate, as in the character armor of "the invulnerable child," who, like a "steel doll," was thought to be impervious to stress (Anthony \& Cohler, 1987). Researchers moved toward recognition of an interaction between nature and nurture in the emergence of resilience, yet tended to hold a pessimistic, narrow view of family influence. Most studies focused on individuals who thrived despite a parent's mental illnest or maltreatment (Wolin \& Wolin, 1993) arid tended to dismiss the family as hopelessly dysfunctional and to seek positive extrafamilial resources to counter the pegative impact. Thus, families were seen to contribute to risk, but not to resilience.

As research was extended to a wide range of adverse conditions, such as growing up in impoverished circumstances, dealing with chmonic medical illness, or recovering from catastrophic life events, traúma, and loss, resilience came to be viewed in terms of an interplay of multiple risk and protective processes over time, involving individual, family, and larger sociocultural influences (Garmezy, 19 $\overline{9} 1$; Masten, Best. \& Garmezy, 1990; Patterson, 2002; Rutter, 1987). Individual vulnerability or the impact of stressful conditions could be outweighed by mediating influences.

In a remarkable longitudinal study of resilience, Werner (1993; Werner \& Smith, 1992) followed the lives of nearly 700 multiculturat children of plantation workers living in poverty on the Hawaiian island of Kauai. By age 18, about two thirds of the at:risk children had done as poorly as predicted, with early pregnancy, needs for mental health services; or trouble in school or with the law: However, one third of those at risk had developed into competent, caring, and confident young adults, with the capacity "to work well, play well, and love well," as rated on a variety of measures. In later follow-ups through midlife, àll but two were still living successful lives. Many had outperformed Kauai children from less harsh backgrounds; more were stably married and employed, and fewer were traumatized by a hurricane that destroyed much of the island. Of note, several who had been poorly functioning in adolescence turned their lives around in adulthood, most often crediting supportive relationships or religious involvement. These findings showed that despite troubled childhood or teen years, there is potential for developing resilience across the life course.

Notably, Werner's research and other emerging studies of resilient individuals all remarked on the crucial influence of significant relationships with kin, intimate

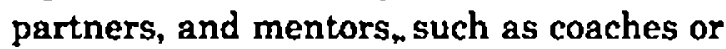
teachers, who supported their efforts, believed in their potential, and encouraged them to make the most of their lives. Still, the prevailing focus on parental pathology blinded many to the family resources that could be found and strengthened, even where a parent's functioning is seriously impaired. A family resilience perspective recognizes parental strengths and potential alongside limitations. Furthermore, grounded in a systemic orientation, it looks beyond the parent-child dyad to consider broader influences in the kin network, from sibling bonds to couple relationships and extended family ties. This approach fundamentally alters the deficit-based lens from viewing troubled parents and families as domaged and beyond repair, to seeing them as challenged by life's adversities, 
with potential for-fostering healing and growth.in all members.

\section{Family Stress, Adaptation, and Resilience}

The concept of family resilience extends beyond seeing individual family members as potential resources for individual resilience to focusing on risk and resilience in the family as a functional unit (Walsh, 1996). A basic premise in this systemic view is that serious crises and persistent adversity have an impact on the whole family. These stresses can derail the functioning of a family system, with ripple effects to all members and their relationships. In turn, key family processes mediate the recovery of all members and the family unit. These processes enable the family system to rally in times of crisis, to buffer stress, reduce the risk of dysfunction, and support optimal adaptation.

Building on theory and research, on family stress, coping, and adaptation (Hill, 1958; McCubbin \& Patterson, 1983; Patterson; 1988, 2002), the concept of family resilience entails more than managing stressful conditions, shouldering a burden, or surviving an ordeal. It involves the potential for personal and relational transformation and growth that can be forged out of adversity (Boss, 2001). Tapping into key processes for resilience, families can emerge ctronger and more resourceful in meeting future challenges. A crisis can be a wake-up call; heightening attention to what matters. It can become an opportunity for reappraisal of priorities, stimulating greater investment in meaningful relationships and life pursuits. Members may discover or develop new insights and abilities. Many families report that through weathering a crisis together. their relationships were enriched and more loving than they might otherwise have been (Stinnett \& DeFrain, 1985).

\section{Social and Developmental Contexts of Risk and Resilience}

A family resilience framework combines ecological and developmental perspectives to view family functioning in relation to its broader sociocultural contextand evolution over the multigenerational life-cycle.

Ecoiogical Perspective. From a biopsy. chosocial systems orientation, risk and resilience are viewed in light of multiple, recursive influences involving individuals, families, and larger social systems. Problems are seen as resulting from an interaction of individual-and family-vulnerability in the impact of stressful life experiences and social contexts. Symptoms may be primarily hiologically based, as in serious illness, or largely influenced by sociocultural variables, such as barriers of poverty 'and discrimination for African-American and immigrant families (McCubbin, McCubbin, McCubbin, \& Futrell, 1998; McCubbin, McCubbin, Thompson, \& Fromer, 1898). Family distress may result from unsuccessful attempts to cope with an overwhelming situation. Symptoms may be generated by a crisis event, such as traumatic loss in the family or the wider impact of a large-scale disaster. The family, peer group, community resources, school or work settings, and other social systems can be seen as nested contexts for nurturing and reinforcing resilience.

Each family s crisis experience will have common (typical) and unique features. Falicov's (1995) useful multidimensional framework for considering cultural diversity locates each family as occupying a complex ecological niche, sharing borders and common ground with other families, as well as differing positions related to such variables as gender, economic status, life stage, 'and position vis-à,vis the dominant culture. A holistic assessment includes the varied contexts. A family resilience framework, likewise, seeks to identify common elements in a crisis situation and effective family responses while also taking into account each family's unique perspectives, resources, and challenges.

Developmental perspective. A developmental perspective is essential in under- 
standing and fostering family resilience. The impact of a crisis event may vary in relation to its timing in individual and fati. ily life-cycle passage. Also, family processes contributing to risk or resilience may vary with emerging challenges over time.

Emerging challenges and responses over time. Most major stressors are not simply a short-term single event, but rather, a complex set of changing conditions with a past history and a future course (Rutter. 1987). Such is the experience of divorce, from an escalation of pre-divorce tensions. through separation and reorganization of households and parent-child relationships; most transition again with remarriage and stepfamily integration (Hetherington \& Kelly, 2002). Given this complexity, no single coping response is invariably most successful: different strategies may prove useful in meeting new challenges that unfold over time:

Family resilience thus involves varied adaptational pathways over time. from a threatening event on the horizon, through disruptive transitions, and subsequent shochwaves in the immediate aftermath and beyond. For instance. how a family approaehes an anticipated loss, buffers stress and manages upheaval, effectively: reorganizes, and reinvests in life pursuits will influence the immediate and longterm adaptation for all members and their relationships (Walsh \& McGoldrick. 1991).

Pile-up of stressors. Some families may do well with a short-term crisis but buckle under the strains of persistent or recurrent challenges. Families may be unfortunate in the concurrence of multiple stressors. A pile-up of internal and external stressors can overwhelm the family. heightening vulnerability and risk for subsequent problems (Boss. 2001: Masten \& Coatsworth. 1998: McCubbin \& Patterson. 1983: Patterson. 2002). One couple's escalating conflict and the husband's hẹavy' drinking brought them to therapy. It was essential to situate these symptoms in the context of the family's barrage of strains and losses over 2 years: in the midst of raising three small children, one with disabilities, the husband's brother died suddenly in a car crash and, overwhelmed by the tragedy, the paternal girandfather suffered a stroke, requiring extensive caregiving; the hesband then lost his job as his company downsized, leaving the family without income or health insurance. Reeling from one crisis to the next, the cumulative pressures were overwhelming. Beyond confict management, therapy helped the couple to recover from their losses, locate resources, and support each other in mastering ongoing challenges.

A family life-cycle perspective. Functioning and symptoms of distress are assessed in the context of the multigenerational family system as itimoves forward across the lifecycle (Carter \& McGoldrick, 1999). At each developmental stage, the balance shifts between stressful events that heighten vulnerability and protective processes that enhance resilience, as well as the relative. influence of family, peers, and other social forces. A family resilience framework focuses on family adaptation around nodal events,.. including both predictable. normative transitions, such as the birth of the first. child. and unexpected or untimely events, such as the death of a young parent.

It is crucial to note the concurrence in timing of symptoms with recent or impending events that have disrupted or threatened the family (Walsh, 1983): For instance, a son's sudden drop in school grades may be precipitated by his father's recent job loss. although family members may not initially note any. connection. -Frequently individual symptoms coincide with stressful transitions', such as parental remarriage, which pose new ahallenges and require boundary shifts and redefinition of roles and relationships. It is important to attend to the extended kin network beyond 
the immediate household. One woman's depression was triggered by the death of her god mother, who had been her mainstay through a difficult childhood.

In assessing the impact of stress events, it is essential to explore how fámily members handled the situation: their proactive stance, immediate response, and long-term "survival strategies. Some approadhes may be functional in the short term but rigidify and become dysfunctional over time. For instance, with a sudden illness, a family must mabilize resources and pull together to meet the crisis, but later must shift gears with chronic disability and attend to other 'members' needs over the long haul (Rolland, 1994).

Legacies of the past. Distress is heightened when current stressors reactivate painful memories and emotions from the past, as in post-traumatic stress reactions. The convergence of developmental and mulkigenerational strains increases the risk for ramplications (Carter \& McGoldrick, 1999). Unresolved past losses of ten resurface with a current or threatened loss. Family members may lose perspective, conflate immediate situations with past events, and become overwhelmed or cut off from painful feelings and contacts. Family stories of past adversity influence future expectations, from an optimistic outlook to catastrophic fears. Many families function well until they reach a point in life-cycle passage that had been traumatic a generation earlier. A woman whose father died suddenly at 50 may become fearful of losing her husband when he reache's the same age.

To assess symptoms of distress in temporal context as well as family and social contexts, a family time line and a genogram. (McGoldrick, Gerson, \& : Shellenberger, 1999) are valuable tools for clinicians and researchers to schematize relationship information, track'systems patterns, and guide intervention planning. Whereas clinicians typically use genograms to focus on problematic,family-of-origin patterns, a resiliencé-based approdch also searches for positive influénces, as in resourceful ways a family dealt with past adversity and models of resilience in the kin network to inspire efforts to master current challenges.

\section{Advantages of a Family Resilience Framework}

Assessment of healthy family functioning is fought with dilemmas. Clinicians and researchers bring their own assumptive maps into every evaluation and intervention, embedded in cultural norms, professional orientations, and personal experiences (Walsh, 2003b). Moreover, with social and economic transformations of recent decades and a growing multiplicity of family arrangements, no single model of family health fits all. In fact, family diversity has been common throughout history and across cultures and a growing body of research reveals that well-functioning families and healthy children can be found in a variety of formal and informal kinshipiarrangements (Walsh, 2003ā). What matters most in dealing with adversity are effective family processes, involving the quality of caring; committed relationships.

Systems-oriented family process research over the past two decades has provided some empirical grounding for assessment of healthy couple and family functioning. However, family assessment typologies tend to be static and acontextual, offering a snapshot of interaction patterns but lacking a contextual view in relation to a family's resources and constraints and their emerging challenges over time. In clinical practice, families most often are seen in periods of crisis, when distress and differences from norms are too readily assumed to be signs of family pathology.

A family resilience framework offers several advantages. By definition, it focuses on'strengths under stress, in the midst of.crisis and in overcoming adversity (Walsh, F., 2003c). Second, it is assumed that no single model fits all families or 
their situations. Functioning is assessed in context i.e., relative to each family's values, structure, resources, and life challenges. Third, processes for optimal functioning and the well-being of members are seen to vary over time, as challenges unfold and families evdlve across the life-cycle. While no single model of family health fits all, a family resilience perspective is grounded in a deep conviction in'the potential for family recovery and growth out of adversity.

\section{KEY PROCESSES IN FAMILY RESILIENCE}

The family resilience framework I have developed to guide clinical practice is informed by clinical and social science research seeking to understand crúcial variables contributing to individual resilience and well-functioning families. It serves as a conceptual map to identify and target key family processes that can reduce stress and vulnerability in high-risk situations, foster healing and growth out of crisis, and empower families to overcome prolonged adversity. The framework draws together findings from numerous studies, identifying and synthesizing key processes within three domains of family functioning: family belief systems. organization pattems, and communication processes (Walsh, 1998). Table 1 presents an outline of key processes for family resilience, which are described briefly.

\section{Family Belief Systems}

Family belief systems powerfully influence how we view a crisis, our suffering, and our options (Wright, Watson, \& Bell, 1996). Shared constructions of reality emerge through family and social transactions; in turn, these belief systems organize family processes and approaches to crisis situations and they can be fundamentally altered by such experiences (Reiss, 1981). Whether as a personal tragedy or a catastrophic event, àdversity generates a crisis of meaning and potential disruption of integration. Resilience is fostered by. shared, facilitative beliefs that increase options for problem resolution, healing, and growth. They help members make meaning of crisis situations facilitate a hopeful, positive outlook; and offer transcendent or spiritual moorings.

\section{Making Meaning of Adversity}

High functioning families have a strong affiliative value (Beavers \& Hampson, 1990): Fundamental to resilience, they approach adversity as a shared chanenge and hold a relational view of strength in contrast to the American cultural ethos of the "rugged individual." "We shall" overcome," the rallying song of the-1960's civil rights movement and contemporary social justice movements worldwide, expresses this core belief: in joining together, individuals strengthen their ability to overcome adversity.

Well-functioning families have an evolutionary sense of time and becominga continual process of growth and change across the life-cycle and the generations (Beavers \& Hampson, 1990). A family life-cycle orientation helps members to see disruptive transitions also as milestones in their shared life passage. By normalizing and contextualizing distress, family members can enlarge their perspective to see their reactions and difficulties as understandable in light of a painful loss or daunting obstacles. The tendency for blame, shame, and pathologizing is reduced in viewing their complicated feelings and dilemmas as "normal," i.e., common and expectable among families facing similar predicaments.

In grappling with adverşity, families do best. when hèlped to gain a sense of coherence (Antoniovsky, 1987; Antonovsky \& Sourani, 1988), by recasting:a crisis as a challenge that is comprehensible, manageable, and meaningful toitackle. It involves efforts to clarify the $e^{i}$ nature of problems and available resources. The 
Table

Key Processes in Family Resilience

Belief Systems

1. Make Mleaning of Adversity:

- View resilience as relationally based vs. "rugged individual"

- Normalize, contextualize adversity and distress

- Sensè of coherence: crisis as meaningul, comprehensible, manageable challenge

- CausaVexplanatory attributions: How could this happen? What can be done?

2. Positive Outlook

- Hope, optimistic bias; confidence in overcoming adds

- Courage and en-courage-ment; affirm strengths and focus on potential

- Active initiative and perseverance (Can-do spirit)

- Master the possible; accept what can't be changed

3.'Transcendence and Spiritunlity.

- Larger values, purpose

- Spirituality: faith. congregational support, healing rituals

- Inspiration: envision new possibilities: creative expression; social action

- Transformation: learning, change. and growth from adversity

Organizational Patterns

4. Flexibility?

- Open to change: rebound, reorganize, adapt to fit yew challenges

- Stability through disruption: continuity, dependability. follow-through

- Strong authoritative leadership: nurturance, protection, guidance

- Varied family forms: cooperative parenting/caregiving teams

- Couple/Co-parent relationship: equal partners.

5. Connectedness.

- Mutual support, collaboration. and commitment

- Respect individual needs, differences, and boundaries

- Seek reconnection, reconciliation of wounded relationships

6. Social and Economic Resources

- Mobilize kin, social, and community networks; seek models and mentors

- Build financial security; balance workffamily'strains

Communication / Problem-solving

7. Clarity

- Clear, consistent messages (words and actions)

- Clarify ambiguous information; truth-seeking/truth-speaking

8. Open Emótional Expression

- Share range of feelings (joy and pain, hopes and fears)

- Mutual empathy: tolerance for differences

- Take responsibility for own feelings, behavior, avoid blaming '

- Pleasurable interactions; humor

9. Collaborative Problem-solving

- Creative brainstorming; resourcefulness; seize opportunities

- Shared decision-making; conflict resolution: negotiation, faimess, reciprocity

- Focus on goals; take concrete steps; build on sujccess; learn from failure

- Proactive stance: prevent problems; averhcrises; prepare for future challenges

Family Process, Vol. 42, No. 1; 2003 O FPI, Inc. 
meaning of adversity and beliefs about what can be done vary with different cultural norms: some are more fatalistic while others stress personal responsibility and agency. (Walsh, 1998). A family's subjective appraisal of a crisis situation and their resources'can influence their coping response and adaptation (lazarus \& Folkman, 1984). Family members attempt to make sense of how things have happened through causal or explanatory attributions. When a crisis event strikes like a bolt out of the blue, as did the terrorist attacks on $9 / 11$. ambiguity about the causes and the human casualties, along with uncertainties about future secirity, complicate the challenges of meaning-making and recovery Walsh. 2002b). Efforts to clarify ambiguous losses, to learn whether and how a loved one died, and to recover remains of a body can facilitate the healing process (Boss. 1999). Communal rituals assist survivors in coming to terms with unbearable grief and in living beyond loss.

\section{Positive Outlook}

Considerable research documents the strong effects of a positive outlook in coping with stress, recovery from crisis, and overcoming barriers to success. Hope is to the spirit what oxygen is to the lungs: It fuels energy and efforts to rise above adversity. Hope is a future-oriented belief:-no matter how bleak the présent. a better future can be envisioned. In problem-saturated conditions. it is essential to rehindle hopes and dreams in order to see possibilities. tap into potential resources, and-strive to surmount obstacles toward aspirations. Hope for a better life for their children keeps many struggling parents from being defeated by their immediate plight.

High-functioning families have been found to hold a more optimistic view of life (Beavers \& Hampson, 1990). Seligman's (1990) concept of learned optimism has particular relevance for resilience. His earlier research on "learned helplessness" showed that with repeated experiences of futility and failure, people stop trying and become passive and pessimistic. generalizing the belief that bad things always happen to them and that nothing they can do will matter. Seligman then reasoned that optimism could be learned, and helplessness and pessimism unlearned, through experiences of successful mastery, building confidence that one's efforts can make a difference. Hè cautioned, however, that a positive mindset is not sufficient for success if life conditions are relentlessly harsh, with few opportuni-. ties to rise above them: As Aponte (1994) notes, many families who feel trapped in impoverished, blighted communities lose hope, suffering a deprivation of both "bread" and "spirit." This despair robs them of meaning, purpose, and a sense of future possibil: ity. To be sustained, a positive outlook must be reinforced by successful experiences and a nurturing community context.

Similar to an optimistic bias, epidemiologists find that "positive illuslons" sustain hope in dealing with adversity, such as a life-threatening illness (Taylor, S., 1989; Taylor S., Kemeny, M., Reed, G., et al., 2000). Unlike denial, there is awareness of a grim reality, such as a poor prognosis, and a choice to believe they can overcome the odds againist them. This positive bias fuels efforts that can reduce risk and maximize the chances of success. For instance, when one family was told that their child had an illness with only a $10 \%$ rate of recovery the parents reasoned, "Someone. has to be in that $10 \%$, so why not us? Let's do all we can to get there."

Affirming family strengths and potential in the midst of difficulties helps families to counter a sense of helplessness; failure, and blame while it seinforces pride, confidence, and a "can do" Epirit. Encouragement bolsters courage to take initiative and persevere in efforts to master a harrowing. ordeal: The courage and determination shown in facing hardships in the everyday life of ordinary. families often goes 
unnoticed. One young girl was amazed by her mother's resilience-that she worked all night and ran errands all day, never giving up and always remembering to give her children lunch money and show them she loved them.

Initiative and perseverance-hallmarks of resilience-are fueled by unwavering shàred confidence through an ordeal: "We alwaysbelieved we would find a way." This conviction bolsters efforts and makes family members active particlpants in seizing opportunities and searching for solutions. By showing confidence that they will each do their best, families support efforts and build competencies. One man credited his endurance in recovery from a spinal cord injury to his wife's unfailing encouragement and their rock-solid relationship. At times when he felt like giving up on life, this "lifeline" restored his determination to engage in every means to regain functioning as fully as possible.

Mastering the art of the possible is vital for resilience, since some things cannot be changed (Higgins, 1994). For families, it involves taking stock of their situation-the challenges, constraints, and resources-and then focusing energies on making the best of their options. This requires acceptance of that which is beyond their control. Instead of being immobilized, or trapped in a powerless victim position, a family's focus is directed toward ongoing and future possibilities i.e., playing the hand that is dealt as well as possible. Although past events can't be changed, they can be recast in a new light that fosters greater comprehension and healing. When immediate problems are overwhelming or events are beyond control, family members can be encouraged to.carve out parts that they can master. For instance, family members may not be able to influence the outcome of a terminal illness, but they can become meaningfully engaged in caregiving and end-of-life preparations, easing suffering, and making the most of the time they have left. Families with an Eastern philosophical or religious orientation tend to have greater ease in accepting things beyond their control or comprehension whereas those with a Western-mastery orientation find difficulty yielding control and instrumental problemsolving tendencies. Family members often report that by being more fully present with loved ones, this most painful time became the most precious in their relationship. In the aftermath of loss, survivors are helped by finding ways to transform the living presence of a loved one into cherished memories, stories, and deeds, which carry on the spirit of the deceased and best aspects of their relationship.

\section{Transcendence and Spiriluality}

Transcendent beliefs and practices provide meaning and purpose beyond ourselves, our families, and our immediate troubles (Beavers \& Hampson, 1990). Most families find strength, comfort, and guidance in adversity through connections with their cultural and religious traditions (Walsh, 1999b). Rituals and ceremonies facilitate passage through significant transitions and linkage with a larger community and common heritage (ImberBlack \& Roberts, 1992). Suffering, and often the injustice or senselessness of it, are ultimately spiritual issues (Wright et al., 1996). Spiritual resources, in deep faith, practices such as prayer and meditation, and religious/congregational affiliation have all been found to be wellsprings for resilience (Werner \& Smith, 1992). Many. find spiritual nourishment outside of formal religion, e.g., deep personal connection with nature, music and the arts, or a higher power. Studies of successful African. American families find that strong faith and congregational involvement help them to rise above barriers of poverty and racism (Boyd-Franklin, 1999). In health crises, medical studies suggest that faith, prayer, and spiritual rituals can actually strengthen healing through the influence of emotions 
on the immune and cardiovascular systems (Dossey, 1993; Weil, 1994). While faith can make a difference, we must be cautious not to attribute failures to recover to lapses in spiritual piety or positive beliefs.

The paradox of resilience is that the worst of times can also bring out our best. A crisis can yield learning, transformation, and growth in unforeseen directions. It can be a wake-up call or epiphany, awakening family members to the importance of loved ones or sparking them to heal old wounds and rearder priorities for more meaningful relationships and life pursuits. Resilient individuals and families commonly emerge from shattering crises with a clearer moral compass and heightened sense of purpose in their lives, gaining compassion for the plight of others (Coles, 1997). The experience of adversity and suffering can inspire creative expression through the arts, as inj jazz. It may spark community action to prevent tragedies. as in Mothers against Drunk Driving. and even a life course committed to helping others or working for social justice (Rolland \& Perry, 1999). It is most important for families in problem-saturated situations to envision a better future through their efforts and for those whose hopes and dreams have been shattered to imagine new possibilities. seizing opportunities for invention, transformation, and growth.

\section{Family Organizational Patterns}

Contempoțary families, with diverse forms, must organize in varied ways to meet the challenges they face. In family organization, resilience is bolstered by flexible structure, connectedness (cohesion). and social and economic resources.

\section{Flexibility: Bouncing Forward}

Flexibility is a core process in resilience. Often the ability to rebound is thought of as "bouncing back" like a spring, to a preexisting shape or norm. However, in the aftermath of most major transitions and crisis events. families can't simply return to "normal" life as they knew it. A more apt metaphor for.resilience might be "bouncing forward," changing to meet new challenges (Walsh, 2002b). Families often need help in navigating new terrain and in undergoing structural reorganization. With such occurrences as parental disability, divorce, or remarriage, famillies must construct a new sense of normality as they recalibrate relationships and reorganize patterns of interaction' to fit new conditions. For instance, a father's disability may require a traditional couple to alter gender-based roles as the mother becomes the sole breadwinner and he assumes primary childrearing responsibilities. If a daughtèr is overburdened in a role as caregiver, siblings can be encouraged to share caregiving demands as a team.

Families also need to buffer and coun; terbalance disruptive changes through efforts to maintain continuity and restore stability (OIson, Russell, \& Sprenkle, 1989). For-instance, the adaptation of immigrant families is fostered by finding ways to sustain connections with valued customs, kin, and the community left behịnd.

Firm, yet flexibly authoritative leadership is most effective for-family functioning and the well-being of children during stressful times. It is especially important for parents and other caretakers to provide nurturance, protection, and guidance through a disruptive transition or crisis. Children and other vulnerable family members especially need assurance of continuity, security, and predicţability throughout the turmoil. For instance, children's adaptation to divorce is facilitated by strong parental leadership and dependability as new single-paxent household structures, visitiation schedules, rules, and routines are set in place.

\section{Connectedness}

Connectedness, or cohesion, is essential. for effective family functioning (Olson $\mathrm{eb}$ al, 1989; Beavers \& Hampşon, 1990). A çrísis 
can shatter family cohesion if members are unable to turn to one another. Resilience is strengthened by mutual support, collaboratidn, and commitment to weather troubled times together. But family members also need to respect each other's individual differences, separateness, and boundaries. They may have quite varied reactions to the same event or may need more or less time to process the experience, depending on such variables as their age or the meaning of a lost relationship.

The complex challenges in stepfamily integration contribute to the higher risk of divorce with remarriage. Most families do best if they can forge workable parenting coalitions across household boundaries, and can knit together biological and step-relations, including step- and half-siblings and extended family. When children are placed in foster care, there are many ways they can. sustain vital connections with their family network through photos, keepsakes, E-mail, letters, visits with extended kin, and links to their cultural and religious heritage.

With the death of a parent; children need reassurance that they won't lose other significant relationships. In the French film Ponette, a small girl survives a car crash in which her mother was fatally injured. As her father takes her to stay with her aunt and cousins while he must go away for his work week, he gives her his watch to wear while he is gone. He tells her that whenever she misses him she should listen to the tick tock of the watch and think of his beating heart and his love for her. He asks if he might take something of hers with him. She considers giving him her favorite stuffed doll, but decides she needs it too muchi so she gives him another instead. This symbolic exchange sustains connection to ease the first transition of many that lie ahead.

\section{Social and Economic Resources}

Kin and social networks are vital lifelines in times of trouble. offering practical and emotional support. The significance of role models and mentors for resilience of at-risk youth is well documented. Involvement in community groups and faith congregations also strengthens resilience. Families who are more isolated can be helped to access these potential resources.

Community-based coordinatèd efforts, involving local agencies and residents, are essential to meet the challenges of a major disaster and widespread trauma and to prepare to avert future threats. Such multisystemic approaches facilitate both family and community resilience (Landau, 2002). In one model program, multifamily groups and parent/teacher networks were organized in lower Manhattan neighborhoods directly affected by the 9/11 terrorist attacks, proving to be a valuable resource to families for sharing their experiences, responding to concerns of their children, supporting one another, and mobilizing concerted action in recovery efforts (Saul, 2002).

The importance of financial security for resilience should not be neglected. A serious or chronic illness can drain a family's economic resources. Persistent unemployment or the loss of a brèadwinner can be devastating. Many studies find that financial strain is the most common risk factor in-single-parent families where parents are overwhelmed and children fare poorly (Anderson, 2003). Most importantly, the concept of family resilience should not be misused to blame families that are unable to rise above harsh conditions by simply labeling them as not resilient. Just as individuals need supportive relationships to thrive, family resilience must be supported by social and institutional policies and practices that foster their ability to thrive, such as flexible work schedules for parents and quality, affordable healthcare and child- and-elder-care services,

\section{Communication/Problem-Solving Processes \\ Communication processes foster resil- ience by bringing clarity to crisis situations,}


encouraging open enotional expression, and fostering collaborative problem-solving. It must be kept in mind that cultural norms vary considerably in the sharing of sensitive information and expression of feelings.

\section{Clarity}

Clarity and congruence in messages facilitate effective family functioning (Epstein, Bishop \& Levin, 1978). Family members may haye different bits and pieces of information or hearsay and fill in the blanks, often with their worst fears. Clarifying and sharing crucial information about crisis situations and future expectations, such as a medical prognosis. facilitate meaning-making. authentic relating, and informed decisionmaking. whereas ambiguity or secrecy can block understanding, closeness, and mastery (Imber-Black. 1995). Shared acknawledgment of the reality and circumstances of a painful loss fosters healing whereas denial and cover-up. especially in stigmatized circumstances such as suicide, can impede recovery and lead to estrangement (Walsh \& McGoldrick, 1991).

When acknowledgment and discussion of life-threatening situations are shut down. anxiety may be expressed in a child's symptoms. One mother brought her 5-year old son: Terell, for an evaluation, fearing he had been sexually abused in his preschool because she repeatedly found him fondling himself. When no indication of sexual abuse was found, it was important for the therapist to explore any stressful events in the family in recent months. The mother then reported that several months earlier. her husband had had exploratory surgery for stomach pains. A cancerous tumor and most of his stomach were removéd. At hospital discharge, he told his wife: "Okay, they said they got it all; I just want to go back to life as normal and not talk about it. To respect her husband's wishes, she told the children
"Daddy's fine" and no more was said. She was managing fine until a recent checkup found something suspicious and the future prognosis was unclear. The parents assumed the children weren't worrying because they hadn't asked any questions. Then she recalled that when the family had said grace before dinner recently, Terell had added: "And please, God, take care of Daddy's tummy." The parents were seen together to open their communication about the life-threatening events and then helped to discuss the situation with their children in ways that fit their value system. Instead of "bouncing back" as if nothing had happened, they were helped to "bounce forward" to integrate the experience into their lives and mesthe challenges of living with threatened loss and uncertainty.

Commonly, well-intentioned families avoid painful or threatening topics, wishing to protect children or frail elders from worry or waiting until the outcome of a precarious situation, such as an unclear medical prognosis. However, anxieties about the unspeakable can generate catastrophic fears. Parents can be helpful by giving assurance that they will keep them. informed as the situation develops and that they are open at any time to discuss questions or concerns. Parents may need guidance on age-appropriate ways to share information and can expect that as children mature, they may revisit issues to gain greater comprehension or bring up emerging concerns. Por example, when a mother has breast cancer, conversations with an eight-year old daughter may focus on concerns about loss. When she reaches puberty, parents may need to respond to her worries that she. too, could develop breast cancer

\section{Emotional Expression}

Open communication, supported by a climate of mutual trust, empathy, and tolerance for differences enables members to share a wide range of feelings that can 
be aroused by crisis events and chronic stress. Family members may be out of sync over time: one may continue to be quite upset as others feel ready to move on. A breadwinner, caregiver, or single parent may suppress strong emotional reactions in order to keep functioning for the family; children may.try to help by stifling their own feelings and needs or trying to cheer up parents. When emotions are intense confict is likely to erupt. When family members feel out of control of a crisis situation, they may attempt to control each other.

Gender socialization leads to common differences in crisis situations, with men tending more to withdraw or become anguy while women are mora likely to express sorrow or anxiety. Masculine stereotypes of strength often constrain men from showing fear, vulnerability, or sadness, which are framed pejoratively as "losing control" and "falling apart." When strong emations can't be shared with loved onos, it increases the risk of substance abuse, symptoms such as depression, self-destructive behaviors, and relational conflict or estrangement. Couples who have lost a child are at heightened risk for divorce, yet those who support each other through the painful ordeal often find their relationship strengthened through the process For relational resilience, cquples and families can be encouraged to share their feelings and comfort one another Finding pleasure and moments of humor in the midst of pain can offer respite and lift spirits.

\section{Collaborative Problem-Solving}

Collaborative problem-solving and conflict management are essential for family resilience. Creative brainstorming and resourcefulness open new possibilities for overcoming adversity and for healing and growth out of tragedy. Shared decisionmaking and conflict resolution involve negotiation of differences with fairness and reciprocity over time, so that partners and family members accommodate to one another. In bouncing forward, resilient families set clear goals and priorities and take concrete steps toward achieving them. They build on small successes and use failures as learning experiences. When aspirations have been shattered, they scan the altered landscape and seize opportunities for growth in new directions. Finally, families become more resourceful when they are able to shift from a crisis-reactive mode to a proactive stance, striving toward a better future while also anticipating and preparing for future clouds on the horizon

Each family must find its own pathways through adversity, fitting their situation. their cultural omentation, and their personal strengths and resources. In one remarkably resilient family, following the shooting death of their oldest son by a gang member in their neighborhood, the mother's deep faith led her to show compassion and forgivertess to the boy who had murdered her son. Although the father owned that he was initially too angry to share her feelings, he respected her decision. and both were able to tolerate and honor each other's positions and work together to help their surviving children with their overwhelming grief. Aided by conversations with a priest and a supportive faith congregation, the father became increasingly able to share his own sorrow with his wife. Facing the killer's mother at a hearing, he embraced her, acknowledging the painful reality that they both had lost their sons: his to a grave and hers to prison. The father channeled his anger productively by launching a community action program for gun control to stop violence and prevent such tragedies for other families.

\section{Olinical Usefuiness of a Family Resilience Framework}

Over the past 2 decades, the field of family therapy has refocused attention from family deficits to family strengths (Nichols \& Schwart2, 2000). The therapeutic relationship has become more collaborative and empowering of client potential, with recognition that successful interventions 
depend more on tapping into family resources than on therapist techniques Karpel, 1986). Assessment and intervention are redirected from how problems were caused to how they can be resolved, identifying and amplifying existing and potential competencies. Therapist and clients work together to find new possibilities in their problem-saturated situation and overcome impasses to change. This positive, futureoriented stance changes the focus from how families have failed to how they can succeed.

A family resilience framework builds on these developments to strengthen families challenged by adversity (Walsh, 1998). It links symptoms of distress with stressful contexts. Families most often come for help in crisis, but often they don't initially connect presenting problems with relevant stress events. A basic premise guiding this approach is that crises and persistent chal. lenges impact the whole family, and in turn, key family processes mediate the adaptation of all members and the family unit.

This framework can serve as a valuable conceptual map to gurde intervention efforts to target and strengthen key processes (described above) as immediate problems are-addressed. Strengthening key processes in each domain has a synergistic influence on other processes. For instance. as families better clarify information and encourage open expression of feelings, members are better able to make meaning of their situation and options. thereby rekindling hope and facilitating more effective problem-solving. As families become more resourceful. risk and vulnerability are reduced and they are better able to meet future challenges. Thus, building resilience is also a preventive measure.

Rather than rescuing so-called "survivors from "dysfunctional families." this approach engages distressed families with respect and compassion for their struggles, affirms their reparative potential, and seeks to bring out their best qualities. Efforts to foster family resilience aim to avert or reduce dysfunction and to enhance family functioning and individual well-being (uuthar et al. 2000). Such efforts have the potential to benefit all family members since they fortify relational bonds and strengthen the family unit.

A family resilience framework can be applied with a wide range of crisis situations and persistent life challenges. Interventions use principles and techniques common among, many strength-based approaches, but attend more centrally to links between presenting symptoms and significant family stressors, identifying and fortifying key processes in coping and adaptation. This approach also gives greater attention to developmental processes over time, as families shift interactional patterns to meet emerging challenges and changing priorities.

Resilience does not mean bouncing back unscathed, but rather struggling well, effectively working through and learning from adversity, and attempoing to integrate the experience into the fabric of their lives (Higgins, 1994). Family members are encouraged to share their stories of adversity, often breaking down walls of silence or secrecy, around painful or shameful issues, to build mutual support and empathy. This approach readily engages so-called "resistant" families, who are often reluctant to come for mental health services out of beliefs (often based on prior experience) that they will be judged as disturbed or deficient and blamed for their problems. Instead, family members are viewed as intending to do their best for one another and struggling with an overwhelming set of challenges. Therapeutic/counseling efforts are directed at mastering those challenges through collaborative efforts.

This approach also encourages steps toward reconciliation of past relational wounds (Walsh, 1998). A son, finding difficulty in giving care to his dying mother because of lingering anger at her alcohol abuse and neglect during his childhood, 
is helped to see her in a new light through learning more about her early life abuse, gaining compassion for her struggles and courage alongside her limitations. Not all family members may be successful in surmounting obstacles, but all are seen to have dignity and worth.

A multisystemic assessment may lead to a variety of interventions or a combination of individual, couple, family, and multifamily group modalities, depending on the relevance of different system levels to problem resolution. Putting an ecological view into practice, interventions may involve community agencies, or workplace, school, healthcare, and other larger systems. Resilience-based family interventions can be adapted to a variety of formats including periodic family consultations or more intensive family therapy. Psychoeducational multifamily groups emphasize the importance of social support and practical information, offering concrete guidelines for crisis management, problem-solving, and stress reduction as families navigate through stressful periods and face future challenges (Anderson, Reiss, \& Hogarty, 1986; Steinglass, 1998). Therapists may identify specific stresses the family is dealing with and then help them develop effective coping strategies, measuring success in small increments, and maintaining family morale. Brief, cost-effective psychoeducational "modules" timed for critical phases of an illness or life challenge encourage families to accept and digest manageable portions of a long-term coping process (Rolland, 1994).

\section{Innovative Family Resilience-Oriented. Programs}

Clinical training, research, and community projects can benefit from being grounded in a family resilience orientation. This framework for training and practice has been applied by our faculty at the Chicago Center for Family Health for work with major crisis experiences, such as serious illness, disability, and loss; recovery from terrorist-related trauma; and work with Bosnian and Kosovar refugee families, as well as a collaborative professional training program in Kosovo to foster family recovery from war-related atrocities and loss (Becker, Sargent, \& Rolland, 2000; Rolland \& Weine, 2000). Programs use this framework to address a range of challenges: (a) adaptation with divorce, single-parenting, and stepfamily reorganization; (b) family stresses and resources with job loss, transition, and new employment: (c) navigating parenting and caregiving challenges; (d) family-school partnerships for the success of at risk youth; and (e) challenges of stigma for gay and lesbian relationships (Walsh, 1999a. 2002a, 2002b).

\section{Navigating New Challenges in a Changing World}

A family resilience framework is especially timely in helping families with unprecedented challenges as they and the world around them are changing at an accelerated pace (Walsh, 2003a). Family cultures and structures are becoming increasingly diverse and fluid. Over an extended family life-cycle, adults and their children are moving in and out of increasingly complex family configurations, each transition posing new adaptational challenges. Amid social, economic, and political upheavals worldwide, families are dealing with multiple losses, disruptions, and uncertainties.

Many families are showing remarkable resilience in creatively reworking their family life. Yet, stressful transitions and attempts to navigate uncharted territory can contribute to individual and relational distress. Nostalgia for the simpler and more secure times of the past can, make adaptations more difficult. A resilienceoriented approach assesses individual, couple, and family distress in relation to this larger context of social change. Families may need help to grieve their actual and symbolic losses as they bounce forward 
in their changing world. Therapists can belp families find coherence in the midst of complexity and maintain continuities in the midst of upheaval to assist in their journey into the future.

\section{CONCLUSION}

As family life and the world around us change so dramatically, we yearn for słrong and enduring relationships. yet we are unsure how to shape and sustain them to meet life challenges. With widespread concern about the breakdown of the family. useful conceptual models such as a family resilience framework are needed more than ever to guide efforts to strengthen couple and family relationships. Family research and practice must be rebalanced from focus on how families fail to how families. when challenged, can succeed in order to move beyond the rhetoric of valuing strong families to support key processes in intervention and prevention efforts. Both quantitative and qualitative research contributions are useful in informing such approaches. As Werner, a leading pioneer in resilience research recently affirmed: (a) resilience research offers a promising knowledge base for practice: (b) the findings of resilience research have many potential applications: and (c) the building of bridges between clinicians. researchers, and policy makers is of utmost importance (Werner \& Johnson. 1999).

This article has presented an overview: of a research-informed family resilience framework, developed as a conceptual map to guide intervention and prevention efforts. A family resilience meta-framework involves a crucial shift in emphasis from family deficits to family challenges. with conviction in the potential for recovery and growth out of adversity. By targeting interventions to strengthen key processes for resilience. families become more resourceful in dealing with crises, weathering persistent stresses, and meeting future challenges. This conceptual framework can usefully be integrated with many strengths-based practice models and applied with a range of crisis situations, with respect for family and cultural diversity. Resilience-oriented services foster family empowerment as they bring forth shared hope, develop new and renewed compefencies, and strengthen family bonds.

\section{REFERENCES}

Anderson, C. (2003). The diversity, strengths, and challenges of single parent households. In F. Walsh (Ed), Normal family processes: Growing diversity and complexity (pp.121152, 3rd ed.). New York: Guilford Press.

Anderson, C.M., Reiss, D., \& Hogarty, G. (1986). Schizophrenia and the family. New York: Guilford Press.

Anthony. E.J., \& Cohler, B. J. (1987). The invulnerable child. New York: Guilford Press.

Antonovsky, A. (1987). Unraveling the mystery of heallh. San Francisco: Jossey-Bass.

Antonovsky: A. \& Sourani. T. (1988). Family sense of coherence and family adaptation. Journal of Marriage and the Family. 50 , 79-92.

Aponte. H. (1994). Bread and spirit: Therapy with the poor. New York: W. W. Norton.

Beavers. WV. R., \& Hampson. R. B. (1990). Successful families: Assessment and intervention. New York: W. W. Norton.

Becker. C.. Sargent, J., \& Rolland, J. S. (2000, Fall). Kosovar Family Professional Education Collaborative. AFTA Newsletter, 80, 26-30.

Boss, P. (1999). Ambiguous loss. Cambridge: MA: Harvard University Press.

Boss. P. (2001). Family stress management: $A$ contextual approach. Newbury Park. CA: Sage Publications..

Boyd-Franklin. N. (1999). Spirituality and religion: Implications for psychotherapy with African-American clients and families. In $\mathrm{F}$. Walsh (Ed.). Spiritual resources in family therapy (pp. 96-103). New York: Guilford Press.

Carter. B.. \& McGoldrick, M. (1999). The expanded family life-cycle: Individual, family, and social-perspectives (3rd ed.). Needham Hill: Allyn \& Bacon.

Coles. R. (1997). The moral inielligence of children. New York: Random House.

Coontz, S. (1907). The way we really are: Coming to terms with America's changing families. New York: Basic Books. 
Cowan, P., Cowan, C. P., \& Schulz, M. (1996). Thinking about risk and resilience in families.

- In E. M. Hetherington \& E. Blechman (Eds.), Stress, coping, and resiliency in children and families (pp. 1-38). Mahwah, NJ: Erlbaum.

Dossey, L (1993). Healing words: The power of prayer and the practice of medicine. New York: Harper.

Epstein, N., Bishop, D., \& Levin, S. (1978). The McMaster model of family functioning. Journal of Marital and.Family Counseling. 4, 19-31.

Falicov, C. (1995) Training to think culturally. A multidimensional comparative framework. Family Process, 34, 373-388.

Garmezy, N. (1991). Resiliency and vulnerability to adverse developmental outcomes associated with poverty. American Behavioral Scientist. 34, $416-430$.

Hetherington, E. M., \& Kelly. J. (2002). For better or for worse: Divorce reconsidered. New York: W. W. Norton \& Co..

Higgins, G.O (1994). Resilient adults. Overcoméris a cruel past. San Francisco: Jossey-Bass.

Hill, R. (1958). Generic feathres of families under stress. Social Casework, 49, 139-150.

Imber-Black, E. (1995). Secrets in families and family therapy. New York: W. W. Norton.

Imber-Black, E., \& Roberts, J. (1992). Riluals for our times. New York: HarperCollins.

Karpel, M. (1986). Family resources: The hidden partner in family therapy. New York: Guilford Press

Kaufiman, J., \& Ziegler, E. (1987). Do abused children become abusive parents? American Journal of Orthopsychiatry. 57, 186-192.

Lazarus, R., \& Folkman, S. (1984). Stress, appraisal, and coping. New York: Springer Publishing Co..

Luthar. S. S., Ciechetti, D., \& Becker, B. (2000). The construct of resilience: A critical evaluation and guidelines for future work. Child Development, $71,543.562$.

Luthar, S. S., \& Ziegler, E. (1991). Vulnerability and competence: A review of research on resilience in childhood. American Journal of Orthopsychiatry, 61, 6.22.

Masten, A. S., Best. K. M., \& Garmezy, N. (1990). Resilience and development: Contributions from the study of children who overcame. adversity. Developmental Psychopathology. 2, 425-444.

Masten, A., \& Coatsworth, J. (1998). The development of competence in favorable. and unfavorable environments. American Psychologist, 53(2), 205.220.

McCubbin, H., McCubbin, M., McCubbin, A.,
\& Futrell, J. (Eds.). (1998). Resiliency in ethnic minority families. Vol. 2. AfricanAmerican families. Thausand Oaks, CA: Sage Publications..

McCubbin, H., McCubbin, M. Thompson, E. \& Fromer, J. (Eds.). (1998). Resiliency in ethric minorily families. Vot, 1 . Native and immigrant families. Thousand Oaks, CA: Sage Publications..

McCubbin, H., \& Patterson, J. M. (1983). The family stress process: The Double ABCX model of adjustment and adaptation. Marriage and Family Review. 6(1/2), 7-37.

McGoldrick, M., Gerson, R., \& Shellenbergèr, S. (1999). Genograms: Assessment and intervention. (2nd. ed.). New York: W. W. Norton \& Co..

Nichols, M., \& Schwartz, R. (2000). Family therapy: Concepts and methods. (4th ed.). Needham Heights, MA: Alyn \& Bacon.

Olson, D.H., Russell, C. S., \& Sprenkle, D. H. (Eds.). (1989). Circumplex model: Systemic assessment and treatment of families: Binghampton, NY: Haworth

Patterson, J. (1988). Families experiencing stress: The family adjustment and adaptation response madel. Family Systems Medicine, $5(2), 202-237$.

Pattẹrson, I, (2002). Integrating family resilience and family stress theory. Journal of Marriage and the Family, li64, 349-360.

Patterson, J \& Garwick, A. (1994). Levels of family meaning in family stress theory. Family Process, 33, 287-304.

Rolland, J.S., \& Perry. A. (1999). Spirituality expressed in community action and social justice: A therapeutic means to liberation and hope. In F. Walsh (Ed.), Spiritual resources in family therapy (pp. 272-292). New York: Guilford Press.

Reiss. D. (1981): The familys fonstruction of realify. Cambridge, MA: Harvard University Press.

Rolland, J. S. (1994). Families, illness and disability: An integrative treatment madel. New York: Basic Books.

Rolland, J. S., \& Weine, S. (2000, Spring). Kosovar Family Professional Educational Collaborative. AFTA Neiusletter, 79, 34-35. Washington, DC: American Family Therapy Academy.

Rutter, M. (1987). Psychosocial resilience and protective mechanisms. American Journal of Orthopsychiatry, 57, 316-331.

Saul, J. (2002, June 29). Promoting communily recovery in lower Manhaltan post-September 11. Plenary presentation, American Family Therapy Academy, 24th Annual Meeting,

Family Process, Vol. 42, No. 1, 20030 FPI, Inc. 
New York.

Seligman. M.E.P. (1990). Learned optimism. New York: Random House.

Stacey, J. (1990). Brave new families: Stories of domestic upheaval in late 20th cenlury America. New York: Basic Books.

Steinglass, P. (1998). Multiple family discussion groups for patients with chronic medical illness. Family Systems Medicine, 16(1/2). $55-70$.

Stingeth. N. \&-DeFrain, J. (1985). Secrets of strong families. Boston: Little. Brown.

Taylor, S. (1989). Posilive illusion: Crealive selfdeception and the healthy mind. New York: Basic Books.

Taylor, S., Kemeny, M., Reed, G., Bower. J.. \& Gruenwald, T. (2000). Psychological resources. positive illusions, and health. American Psychologisl, 55(1), 99-109.

Walsh. F. (1983). The timing of symptoms and critical events in the family life-cycle. In $\mathrm{H}$. Liddle (Ed.), Clinical implications of the family life-c)cle (pp.120-133). Rockville, MD: Aspen Systems Publications.

Walsh. F. (1996). The concept of family resilience: Crisis and challenge. Family Process. 35(3), 261-281.

Walsh. F. (1998). Strengthening fomily resilience. New York: Guilford Press.

Walsh, F. (1999a). Families in later life: Challenges and opportunities. In B. Carter \& M. McGoldrick (Eds.). The expanded family' life-cycle-(pp. 307-326). Needham Heights. MA: Alyn \& Bacion.

Walsh, F. (Ed.) (1999b). Spiritual resources in family therapy. New York: Guilford Press.

Walsh. F. (2002a). A family resilience framework: Innovative practice applications. Family Relations. 5l(2). 130-137.
Walsh, F. (2002b). Bouncing forward: Resilience in the aftermath of September 11. Family Process, 41(1), 34-36.

Walsh, F. (2003a). Changing families in a changing world: Reconstructing family normality. In F.Walsh (Ed.), Normal family processes: Growing diuersity and complexity (3rd ed.). New York: Guilford Press.

Walsh, F. (2003b). Normal family processes: Growing diversity and complexity (3rd ed.). New York: Guilford Press.

Walsh, F (2003c). Family resilience: Strengths forged through adversity. In R. Walsh (Ed.). Normal family processes (3rd ed., pp. 399 423). New York: Guilford Press.

Walsh, F., \& McGoldrick, M. (Eds.). (in press). Living bejond loss: Death in the family (2nd ed.).- New York: W. W. Norton.

Weil, A. (1994). Spontaneous healing. New York: Knopf.

Werner, E. E. (1993). Risk, resilience, and recovery: Perspectives from the Kauai longitudinal study. Developmenl and psychopathology, 5, 503-515.

Wernęr, E.E., \& Smith, R. (1992). Overcoming the odds. Ithaca, NY: Cornell University Press.

Werner, E. E., \& Johnson. J. L. (1999). Can we apply resilience? In M.D. Glantz \& J. L. Johnson (Eds.), Resilience and development. Positive life adaptations (pp. 259-268) New York: Academic Plenum Publishers.

Wolin, S., \& Wolin, S. (1993). The resilient self: How survivors of troubled families rise above adversity. New Yark: Villard Books.

Wright, L., Watson, W.L., \& Bell, J.M. (1996). Beliefs: The heart of healing in families. New "York: Basic Books. 